organic communications

\title{
Boron/Nitrogen Co-doped carbon quantum dots as a high sensitive and selective fluorescent sensor for $\mathrm{PO}_{4}{ }^{3-}$ detection
}

\author{
Azadeh Ostad Chinigar $\odot$, Ashkan Shomali $\odot$ and Hassan Valizadeh \\ Department of Chemistry, Azarbaijan Shahid Madani University, P.O. Box: 53714-161, Tabriz, Iran
}

(Received January 20, 2020; Revised March 25, 2020; Accepted March 27, 2020)

\begin{abstract}
Boron/Nitrogen doped carbon quantum dots (BNCQD) was synthesized and its physiochemical and optical properties were investigated by FT-IR, XRD, XPS, TEM and spectroscopic methods. The freshly prepared BNCQD shows a strong green fluorescence at $400 \mathrm{~nm}$ excitation, and $\mathrm{PO}_{4}{ }^{3-}$ anion can readily turn-on the fluorescence of BNCQD through forming stable complex. Then, we designed a turn-on fluorescence sensor for phosphate ion detection which indicate a high selectivity towards $\mathrm{PO}_{4}{ }^{3-}$ ions in comparison with the other anions with a limit of detection of 0.1 $\mu \mathrm{M}$. It was approved that BNCQD is highly sensitive and selective to detect $\mathrm{PO}_{4}{ }^{3-}$ anion in wastewater.
\end{abstract}

Keywords: B/N-carbon dots; phosphate; sensor @2020 ACG Publications. All right reserved.

\section{Introduction}

Excessive presence of phosphorus species in drinking water and various types of agricultural, domestic, and industrial wastewaters is a serious problem worldwide. ${ }^{1}$ Presence of excess phosphate into the aquatic environment leads to eutrophication which can promote growth of harmful algal and decrease the amount of dissolved oxygen in water. ${ }^{2}$

Therefore, decreasing or removing the phosphate in water is very important function for abbreviating the pollution of water bodies. Various techniques have been reported for phosphate removal successfully, such as chemical precipitation, adsorption, osmosis and biological treatment. ${ }^{3-6}$ High efficiency, simple operation and applicability at lower concentrations in adsorption technique, make it the most widely used method for phosphate removal. ${ }^{7}$

Therefore, trace level detection of phosphate is very beneficial from the point of view of water hygiene. There are many protocols containing doping, surface modifications, and their analytical developments have been reported. ${ }^{8-12}$ Qiu et al used GQD combined with Europium ions as photoluminescent probes for phosphate sensing. ${ }^{13} \mathrm{Jin}$ et al. reported the detection of phosphate ions using of phosphorescence of $\mathrm{Mn}$ doped $\mathrm{ZnS}$ quantum dots. ${ }^{14}$ Dan et al. used $\mathrm{Ag}_{2} \mathrm{~S} \mathrm{QD} /$ metal - organic shell composite as a fluorescent sensor for the detection of Phosphate ion in aqueous solutions. ${ }^{15}$ Phosphate ion detection have also been reported using silver nanoclusters/metal-organic shell composite in aqueous solutions. ${ }^{16}$

\footnotetext{
* Corresponding authors: Email: hvalizadeh2@yahoo.com, Phone:+9833319301; Fax: +9834327522;
} 
In continuation of our interest in preparation and using CQD and modified CQD as a reagent and/or catalyst in chemical reactions, ${ }^{17-19}$ we decided to prepare B-doped CQD and examine its applicability for the sensing of some important anions.

Due to their excellent optical and electronic properties, carbon quantum dots (CQD) are shown as a very interesting compounds from various areas including sensors, bioimaging and catalysis. ${ }^{20-22}$ To overcome some drawbacks such as low quantum yields of pristine CQD, which contain only carbon and oxygen atoms, surface modification as well as doping with elements such as nitrogen was performed to achieve high fluorescence efficiency. ${ }^{23-26}$

Intrinsic properties of carbon materials are effectively tuned by doping with heteroatoms, and new phenomena and unexpected characteristics are produced. There are numerous reports on the doping in graphene by $\mathrm{N}$ and $\mathrm{B}$ substitution of $\mathrm{C}$ to properly change their structural, optical and chemical properties. ${ }^{27-29}$ Doping these heteroatoms in graphene makes it a semimetal or a semiconductor, with possible applications in sensing. ${ }^{30-31}$

Some reported studies have shown that doping with nitrogen can largely improve the fluorescence of doped CQD. ${ }^{32-34}$ Surface modified and element-dopped photoluminescence CQD were used as biocompatible, biodetectors and biosensors. ${ }^{35}$ Liu et al reported the using of N-doped CQD as a glucose sensor. ${ }^{36}$

Herein, we report an efficient fluorescence sensing system for phosphate anion detection based on the boron and nitrogen-doped graphene quantum dots (BNCQD), which was synthesized by using a one-pot MW-assisted simple reaction of boric acid, citric acid and ammonia in an aqueous solution. Phosphate is a fundamental component of the nutritional chain of aquatic microorganisms, and an appropriate indicator of organic pollution in water. ${ }^{33}$ Therefore phosphate tracing is of great important for controlling of eutrophication. Scheme 1 shows the combination of BNCQD and phosphate and the principles of this anion detection concept. Fluorescence intensity is increased by the coordination of phosphate anion to the B atoms in the BNCQD.<smiles>O=C(O)CC(CC(=O)O)C(=O)O</smiles>
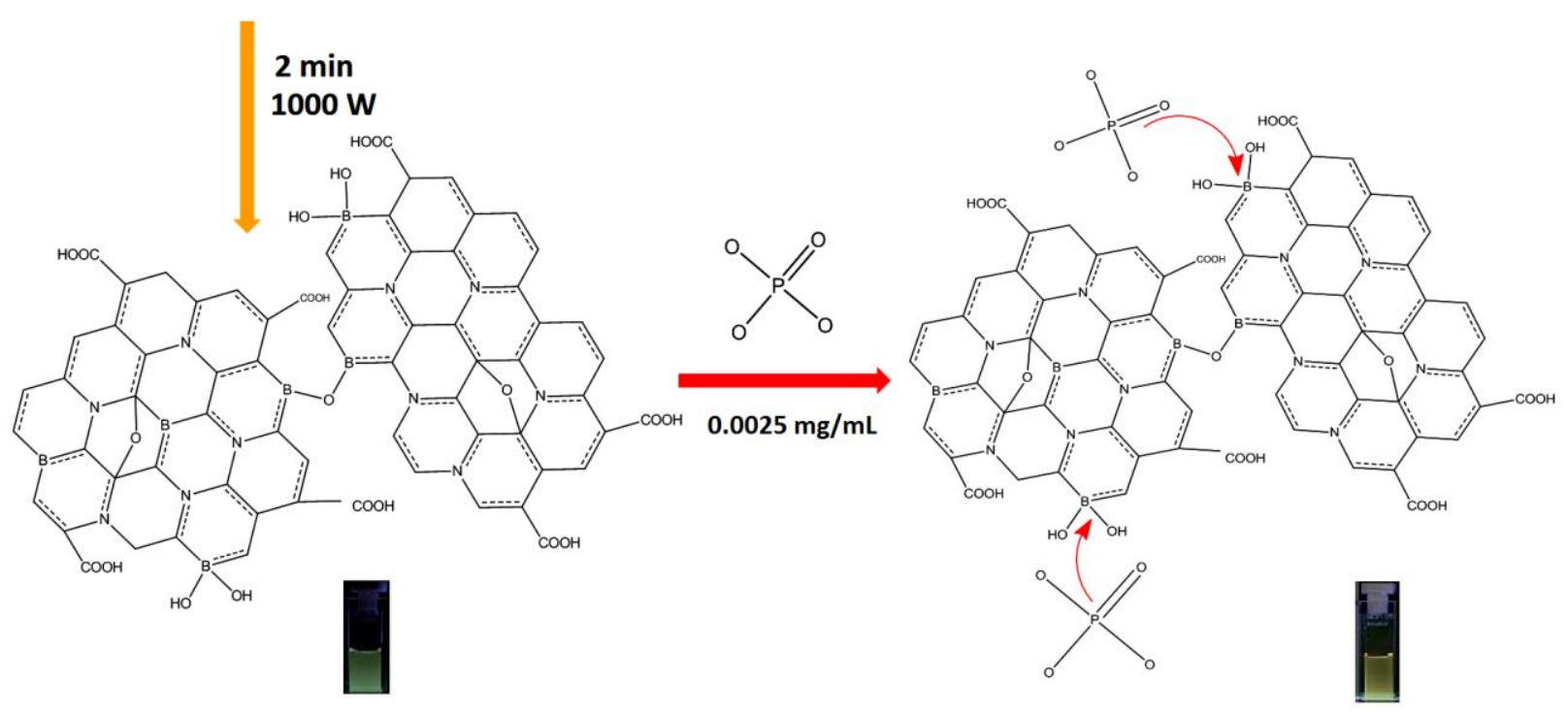

Scheme 1. BNCQD preparation and the effect of phosphate absorption on its fluorescence intensity. 


\section{Experimental}

\subsection{General Information}

All solvents and reagents are industrial and used without further purification. Infrared (FT-IR) spectra of samples in $\mathrm{KBr}$ were recorded by a Bruker PS-15 spectrometer. UV-Vis absorption spectrum was carried out using a UV/VIS/NIR spectrometer (Perkin Elmer lambda 650). The morphology of BNCQDs was observed on a Zeiss EM10C transmission electron microscope (TEM). Analysis of X-ray photoelectron spectroscopy (XPS) were done with an ESCALAB 250.Xi from Thermo Scientific using $\mathrm{Mg}$ X-ray resource. The structure of the nanoparticle was determined using X-ray diffraction pattern (XRD, Bruker, AXS model D8). Fluorescence spectra were measured on a Jasco FP-6500 fluorescence spectrophotometer. MW experiments were conducted in a Milestone MicroSynth apparatus.

\subsection{Synthesis of BNCQD}

Citric acid (1g, $0.052 \mathrm{~mol})$, boric acid $(0.125 \mathrm{~g}, 0.0053 \mathrm{~mol})$ and ammonia $(0.80 \mathrm{~mL}, 18.66 \mathrm{~mol})$ were added in $5 \mathrm{~mL}$ water and stirred vigorously. Then the mixture was heated with full power MWI (1000 $\mathrm{W})$ for 2 minutes. Then the dark-green reaction mixture was cooled to room temperature and deionized water $(5 \mathrm{~mL})$ was added and stirred thoroughly. Then, water was evaporated under the vacuum at $50{ }^{\circ} \mathrm{C}$ and the residual (BNCQD) was collected for further analysis.

\subsection{Synthesis of NCQD}

Citric acid (1 g, $0.052 \mathrm{~mol})$ and ammonia $(0.3 \mathrm{~g}, 0.017 \mathrm{~mol})$ were add in $5 \mathrm{~mL}$ water and heated with full power microwave $(1000 \mathrm{~W})$ for 3 minutes. The light brown liquid obtained was placed in oven under $50{ }^{\circ} \mathrm{C}$ temperature and NCQD were collected.

\subsection{Experimental Conditions}

For sensitivity examination, $\mathrm{Na}_{3} \mathrm{PO}_{4}$ solutions in deionized water were prepared in various concentrations $(0.1-120 \mu \mathrm{M})$. Then, the resultant solution $(5 \mathrm{~mL})$ was added into the deionized aqueous solution of BNCQD $(0.0025 \mathrm{mg} / \mathrm{mL})$ at $25^{\circ} \mathrm{C}$ with the $\mathrm{pH}$ range of 6-8 and immediately mixed thoroughly. After incubation for $10 \mathrm{~min}$, the fluorescence spectrum of the resulting solution was recorded at $\lambda_{\mathrm{ex}}=400$ $\mathrm{nm}$. Described procedure was carried out for all of other salts such as $\mathrm{Na}_{2} \mathrm{CO}_{3}, \mathrm{KOH}, \mathrm{NaOH}, \mathrm{NaNO}_{3}$, $\mathrm{HCN}, \mathrm{Na}_{2} \mathrm{SO}_{4}, \mathrm{AcOH}, \mathrm{HF}, \mathrm{HCl}, \mathrm{HBr}$ and $\mathrm{HI}$.

\subsection{Measurement of the Quantum Yield}

The quantum yield of the synthesized BNCQD and NCQD were determined according to below equation using quinine sulfate as a standard fluorescent.

$$
\mathrm{Y}_{u}=\mathrm{Y}_{s t}\left(\mathrm{I}_{u} / \mathrm{I}_{s t}\right)\left(\mathrm{A}_{s t} / \mathrm{A}_{u}\right)\left(\mathrm{n}_{u}{ }^{2} \mathrm{n}_{s t}{ }^{2}\right)
$$

In this equation $\mathrm{Y}$ is the quantum yield, $\mathrm{I}$ is the measured integrated emission intensity, $\mathrm{n}$ is the refractive index, and A is the extinction. The " $u$ " and " $s t$ " are refered for sample with unknown QY and for standard respectively.

\section{Results and Discussion}

\subsection{Characterization}

B- and N-doped carbon quantum dots (BNCQD) was prepared under MW irradiation by using boric acid as the boron source and ammonia as the source of nitrogen (Step 1, Scheme 1). Transmission electron microscopy (TEM) image in Figure 1 shows that the particle size distribution of BNCQD is in the range of $5-30 \mathrm{~nm}$ and that the average size is approximately $15 \mathrm{~nm}$. 


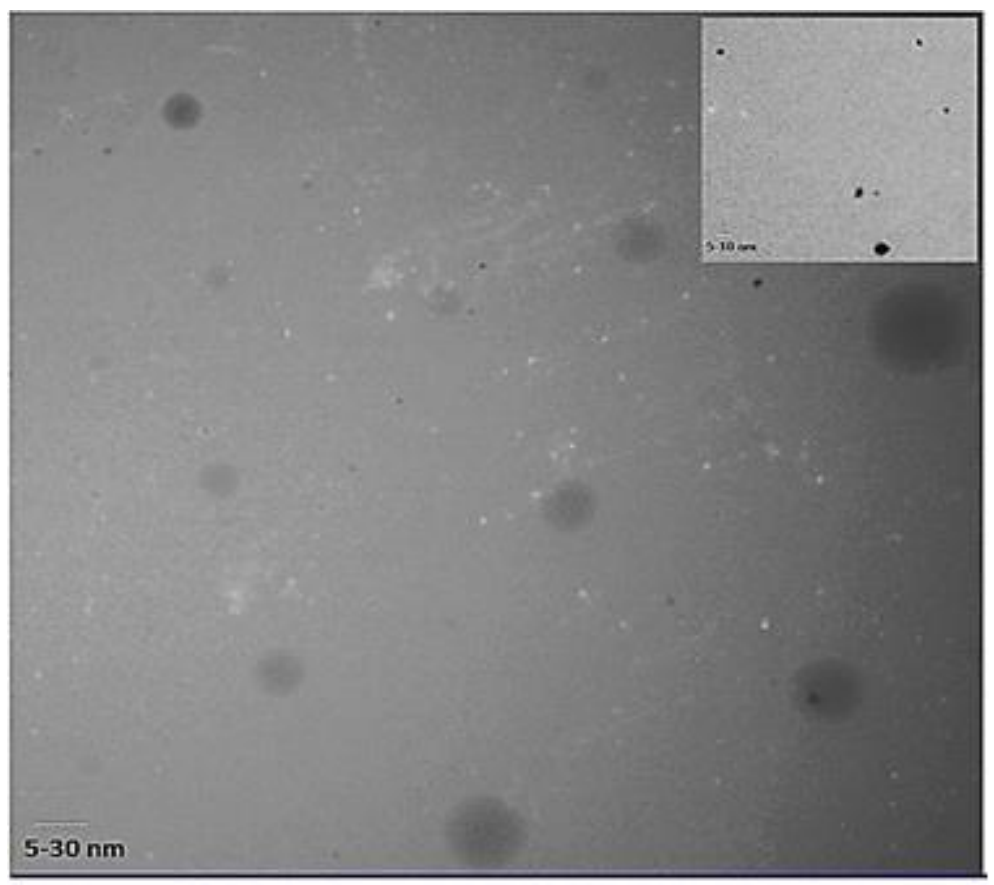

Figure 1. TEM image of BNCQD

Figure 2 shows the XRD pattern of the crystalline structure of BNCQD and exhibit a weak broad peak at around $22.0^{\circ}$ belong to the (002) planes of CQD. ${ }^{37-38}$ the interlayer spacing of BNCQD was 3.82 $\AA$ which is larger in comparison with bulk graphite $(3.34 \AA$ ). The further interlayer distance is related to the functional groups containing on the surface of BNCQD.

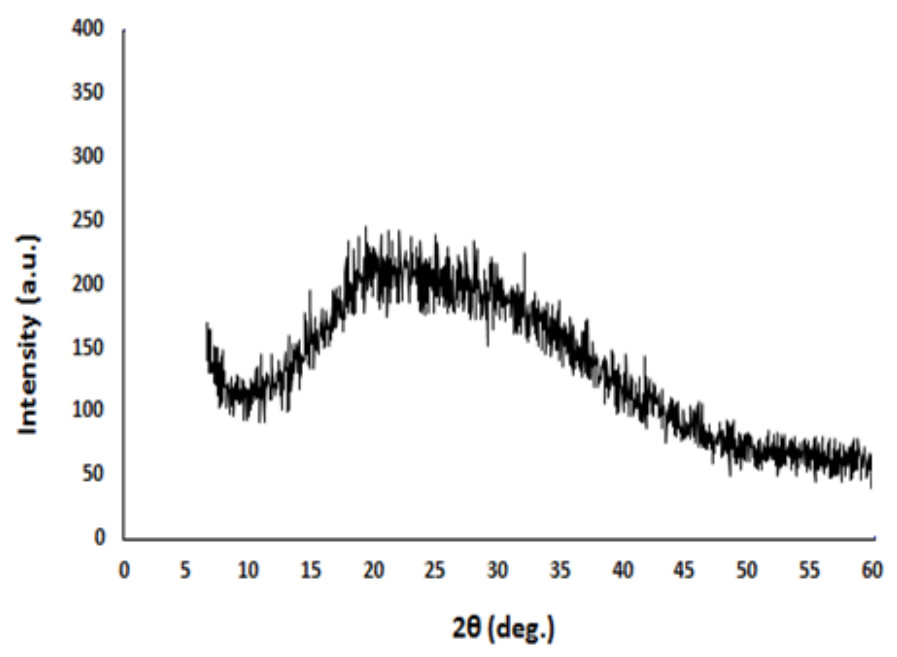

Figure 2. XRD pattern of BNCQD

XPS survey spectrum of BNCQD (Figure 3) shows the presence of $\mathrm{C}, \mathrm{O}, \mathrm{N}$ and $\mathrm{B}$ with atomic percentages of $32.73 \%, 57.34 \%, 8.73 \%$, and $1.20 \%$ and the corresponding $\mathrm{C} 1 \mathrm{~s}, \mathrm{O} 1 \mathrm{~s}, \mathrm{~N} 1 \mathrm{~s}, \mathrm{~B} 1 \mathrm{~s}$ peaks are located at ca. 286.74, 532.75, 401.11 and $192.44 \mathrm{eV}$, respectively. Therefore, the successful incorporation of $\mathrm{B}$ atoms into the CQD was confirmed. As shown in Figure $3 \mathrm{~b}$ the high resolution $\mathrm{C} 1 \mathrm{~s}$ spectrum confirmed the O-rich groups, such as $\mathrm{C}-\mathrm{O} / \mathrm{C}-\mathrm{N}, \mathrm{C}=\mathrm{C}$ and $\mathrm{O}-\mathrm{C}=\mathrm{O}$. In the high resolution $\mathrm{B} 1 \mathrm{~s}$ spectrum (Figure 3d), the peaks at the range of $192-193 \mathrm{eV}$ correspond to the $\mathrm{B}-\mathrm{C}$ bonds present in BNCQD 
structure. The presence of $\mathrm{B}-\mathrm{N}$ and $\mathrm{C}-\mathrm{N}$ bonds is also confirmed from the high resolution $\mathrm{N} 1 \mathrm{~s}$ spectrum (Figure 3e). The existence of $\mathrm{C}-\mathrm{B}$ bonds in the BNCQD can be confirmed from the all these results.
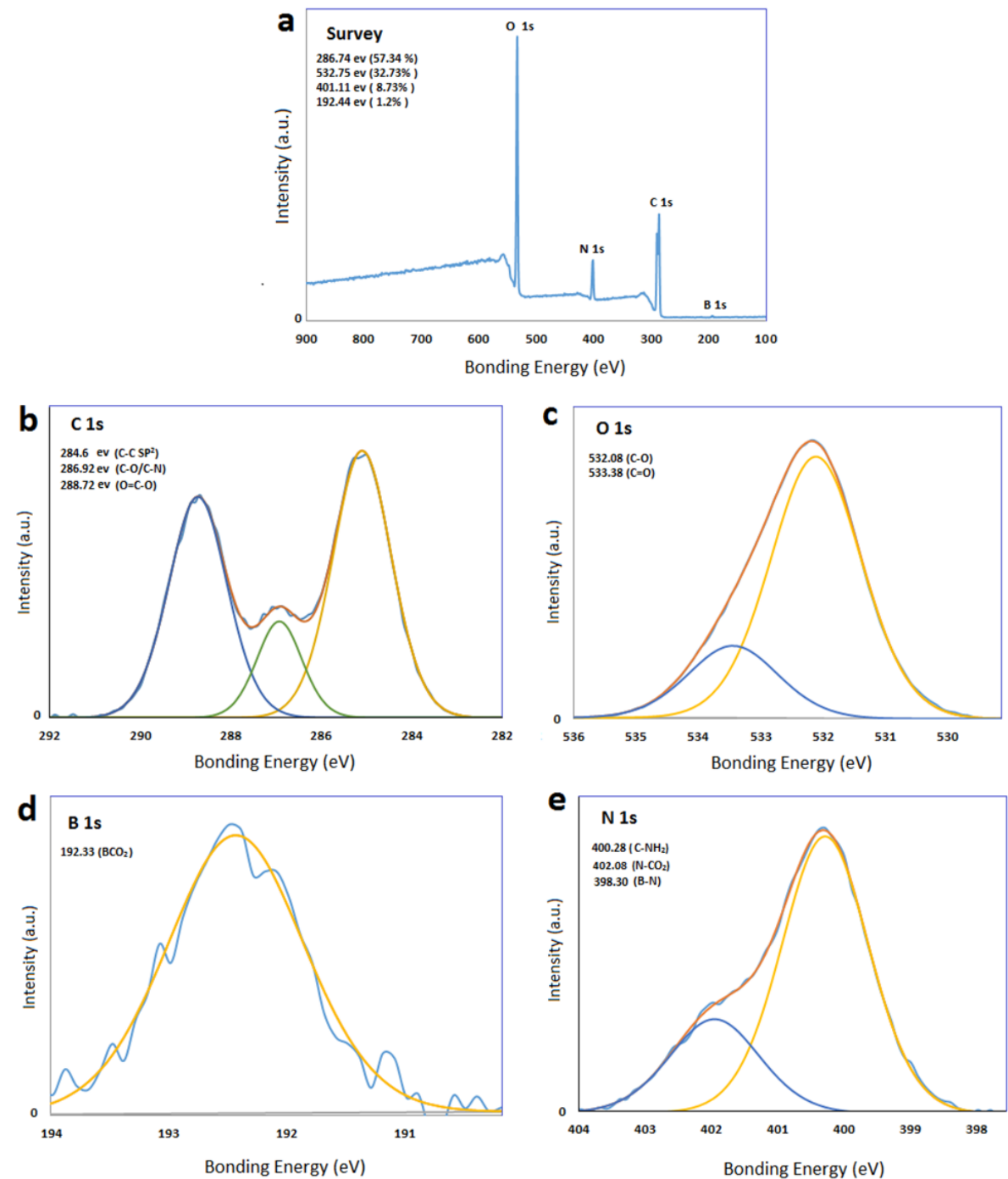

Figure 3. (a) X-ray photoelectron spectrum of BNCQD, (b) C1s spectrum, (c) O1s spectrum, (d) B1s spectrum, (e) N1s spectrum

The FT-IR spectra of the CQD and BNCQD sample are given in Figure S1 (see supporting information). Broad absorption band at $3100-3500 \mathrm{~cm}^{-1}$ from BNCQD spectrum is assigned to $\mathrm{O}-\mathrm{H}$ and $\mathrm{N}-\mathrm{H}$. Carbonyl $\mathrm{C}=\mathrm{O}$ groups show an absorption band at approximately $1710 \mathrm{~cm}^{-1}$. The hydrophilicity of BNCQD is achieved via the presence of these functional groups. ${ }^{39}$ Two strong absorption peaks at 1432 and $1192 \mathrm{~cm}^{-1}$ are attributed to $\mathrm{B}-\mathrm{O}$ stretching vibration and $\mathrm{B}-\mathrm{C}$ absorption band respectively and this is a strong evidence for the presence of $\mathrm{B}$ atom in the BNCQD structure. Two particular peaks at 1340 and $817 \mathrm{~cm}^{-1}$ are observed, which are associated with the $\mathrm{B}-\mathrm{N}$ bond stretching vibration and the $\mathrm{B}-\mathrm{N}-\mathrm{B}$ bending vibration, respectively and therefore the presence of $\mathrm{N}$ atom in structure is approved.

\subsection{Optical Properties}

Optical properties of obtained BNCQD were investigated using UV-Vis and Fluorescence techniques. Figure 4 shows the UV/Vis absorption spectrum and the PL spectra of BNCQD. Typical absorption peaks at $220 \mathrm{~nm}$ and $330 \mathrm{~nm}$ are observed which assigned to the $\pi-\pi^{*}$ transition of aromatic $\mathrm{sp}^{2}$ domains and $\mathrm{n}-\pi^{*}$ transition of functional groups on the BNCQD respectively. ${ }^{40}$ As shown in Figure 
4b, BNCQD exhibits an optimal emission peak at $503 \mathrm{~nm}$ under excitation at $400 \mathrm{~nm}$, thus it shows a strong green light emission under PL irradiation. In addition, the fluorescence quantum yield (QY) of the resulted BNCQD was about $28.4 \%$ using quinine sulfate as the calculated standard reference.

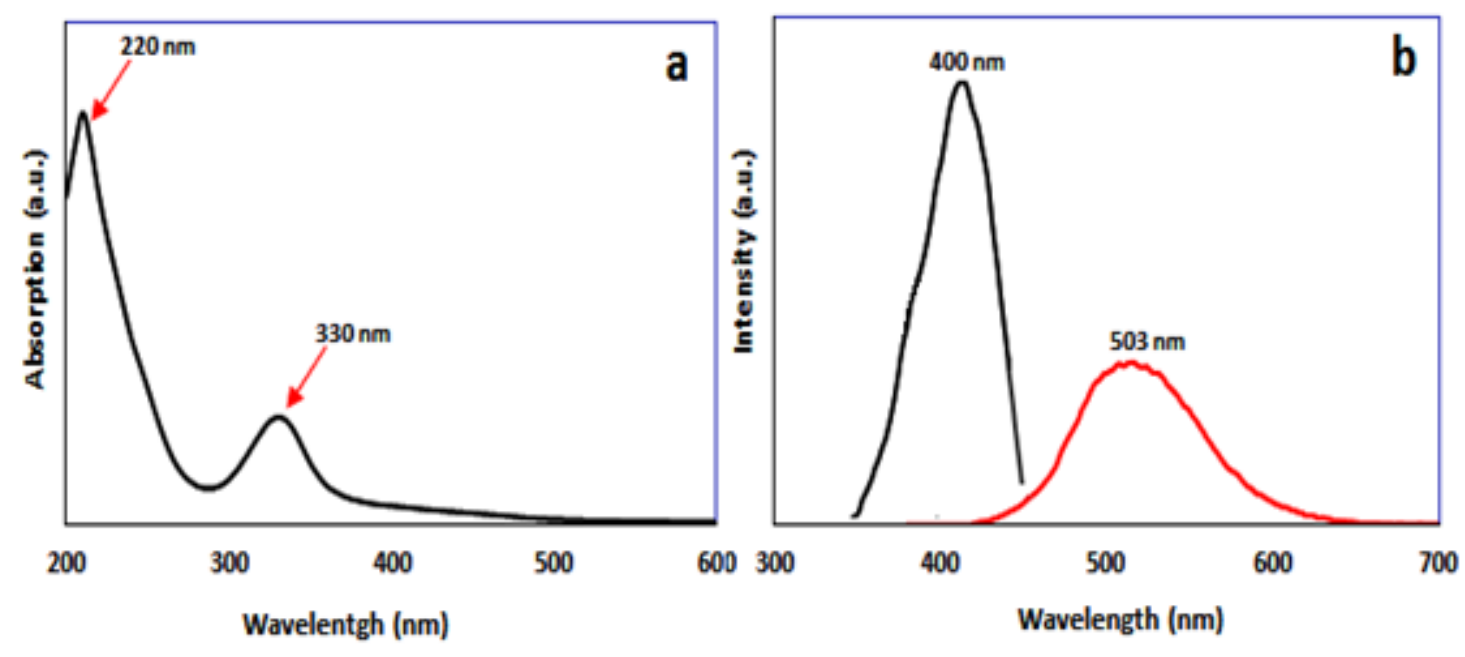

Figure 4. a) UV-vis absorption and b) PL spectra of the BNCQD: excitation (black), and emission (red)

\subsection{Mechanism of Phosphate Ions Detection}

For comparison of the effect of $\mathrm{PO}_{4}{ }^{3-}$ on fluorescence of BNCQD and NCQD, the fluorescence spectra of these compounds are shown in the presence and absence of $\mathrm{PO}_{4}{ }^{3-}$ in Figure 5. BNCQD shows a strong fluorescence emission peak at $503 \mathrm{~nm}$, whereas NCQD (with quantum yield about 26.8) exhibit a weak emission peak at $503 \mathrm{~nm}$ and it results that fluorescence quantum yield of BNCQD is considerably higher than that of NCQD. It can be suggested that the coordination of carboxylate groups on the BNCQD surfaces to $\mathrm{B}$ atom in the structure of BNCQD leads to the formation of nonfluorescent BNCQD aggregates and decreasing of fluorescence. It is interesting to note that an obvious increase in fluorescence intensity of BNCQD is observed in the presence of $\mathrm{PO}_{4}{ }^{3-}$, whereas it has only a negligible influence on the florescence of NCQD.

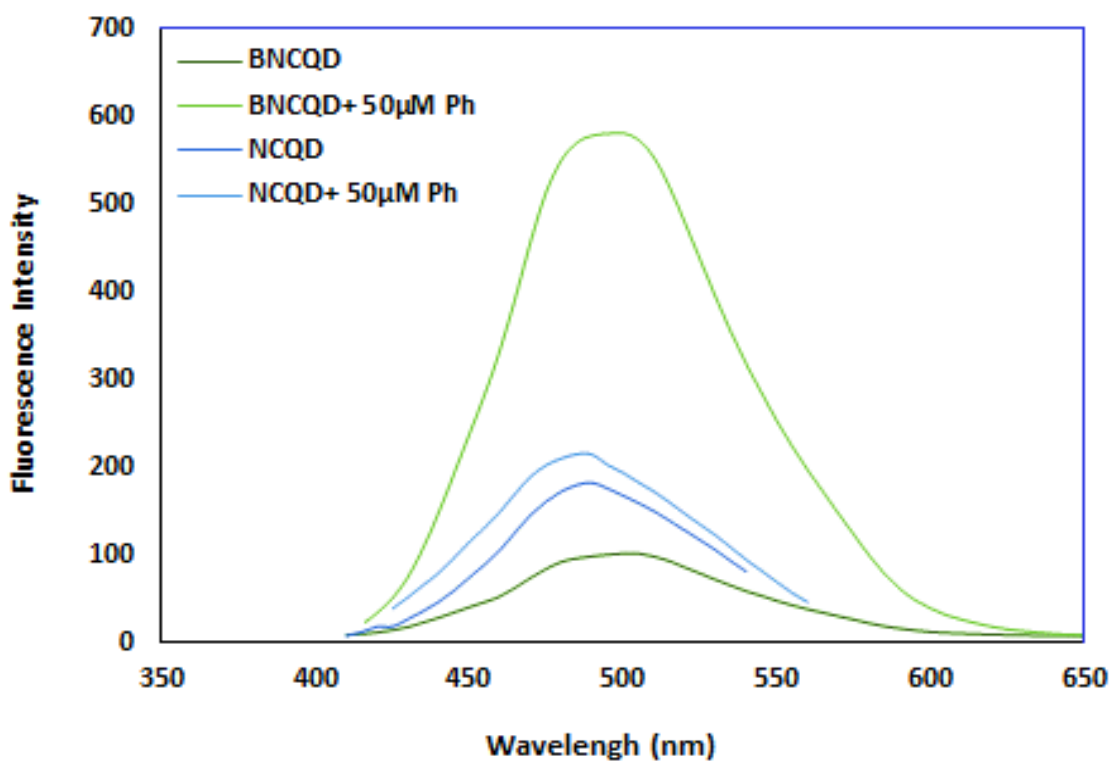

Figure 5. Fluorescence spectra of BNCQD and NCQD in the presence and absence of $\mathrm{PO}_{4}{ }^{3-}$. 
The capability of a BNCQD sensing system towards the detection of $\mathrm{PO}_{4}{ }^{3-}$ was evaluated by measuring the changes in fluorescence intensity of this compound at $503 \mathrm{~nm}$ with varying $\mathrm{PO}_{4}{ }^{3-}$ concentration (Figure 6). It is clearly seen that BNCQD has a positive response towards $\mathrm{PO}_{4}{ }^{3-}$ and the fluorescence intensity at $503 \mathrm{~nm}$ increases by the $\mathrm{PO}_{4}{ }^{3-}$ concentration addition. As can be seen, the increasing in concentration of $\mathrm{PO}_{4}{ }^{3-}$ from 0 to $120 \mu \mathrm{M}$ leads an obvious enhancement in fluorescence intensity in the emission band at $503 \mathrm{~nm}$. In fact, in the absence of phosphate ions, $\mathrm{B}^{3+}$ ions can coordinate with the carboxylate groups on the surface and doped nitrogen atoms in the carbon quantum dots, as a result, fluorescence of $\mathrm{BNCQD}$ are quenched through energy transfer or electron transfer processes.

In the present of $\mathrm{PO}_{4}{ }^{3-}$ ions, they can donate their electron to vacancy orbitals of $\mathrm{B}$ atoms to create stable bonds and resulting increased fluorescence intensity of BNCQDs, again. Because $\mathrm{B}^{3+}$ ions exhibition a more tend to phosphor donor electron groups in $\mathrm{PO}_{4}{ }^{3-}$ ions toward the oxygen in carboxylate groups and nitrogen of carbon dots. A linear relationship between the increased fluorescence intensity of BNCQDs and the concentration of $\mathrm{PO}_{4}{ }^{3-}$ is observed (inset of Figure 6, 0.1 to $120 \mu \mathrm{m}, \mathrm{R}^{2}=0.9989$ with the calibration equation is $\left.\mathrm{Y}=2.4911+0.0479\left[\mathrm{PO}_{4}{ }^{3-}\right]\right)$. The limit of detection for phosphate ion was calculated to be $0.1 \mu \mathrm{M}$ according to $S_{\mathrm{m}}$ equation which is comparable to the world health organization standard $(0.2 \mu \mathrm{M})$ for drinking water. ${ }^{41}$
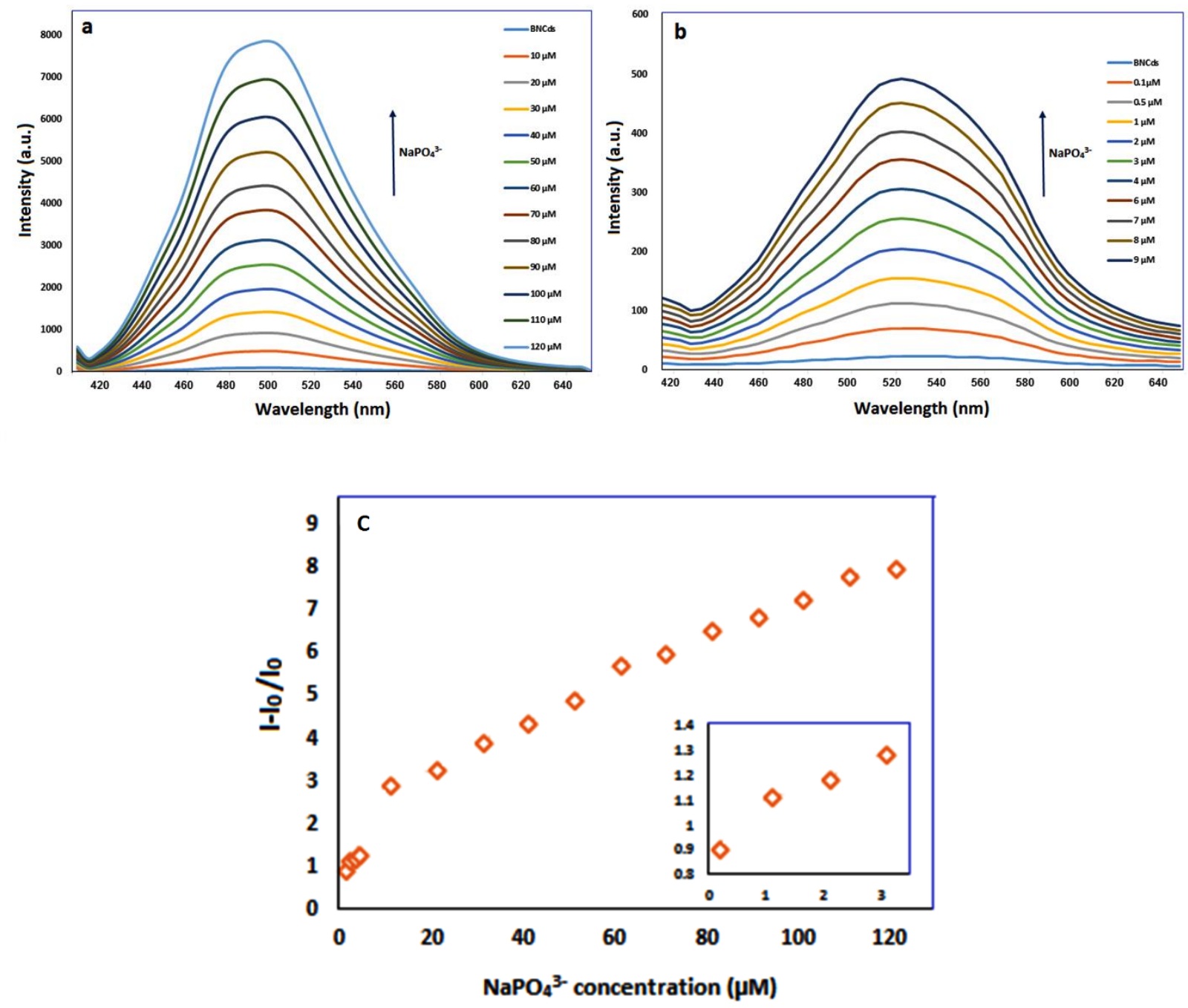

Figure 6. $\mathbf{a}$ and $\mathbf{b}$ ) Fluorescence spectra of BNCQD aqueous solution upon addition of $\mathrm{PO}_{4}{ }^{3-}$ in different concentrations at $400 \mathrm{~nm}$, c) Relationship between $\left(\mathrm{I}-\mathrm{I}_{0} / \mathrm{I}_{0}\right)$ and $\mathrm{PO}_{4}{ }^{3-}$ from 0.1 to $120 \mu \mathrm{M}$. $\mathrm{I}_{0}$ and $\mathrm{I}$ are the PL intensities of BNCQD at $400 \mathrm{~nm}$ excitation in the absence and presence of $\mathrm{PO}_{4}{ }^{3-}$ ions respectively. 
To compare the selectivity of $\mathrm{BNCQD}$ against $\mathrm{PO}_{4}{ }^{3-}$ ions, we perform titration with others anions. The selectivity of the fluorescent sensor for $\mathrm{PO}_{4}{ }^{3-}$ over other substances such as $\mathrm{CO}_{3}{ }^{2-}, \mathrm{NaOH}$ and $\mathrm{KOH}$ was evaluated and the results are shown in Figure 8. As shown in Figure 7, no clear increase is observed with other ions in comparison with $\mathrm{PO}_{4}{ }^{3-}$ which demonstrate high selectivity for $\mathrm{PO}_{4}{ }^{3-}$. Therefore, BNCQD can be introduced as an excellent sensitive and high specific sensor for $\mathrm{PO}_{4}{ }^{3-}$ detection in real samples.

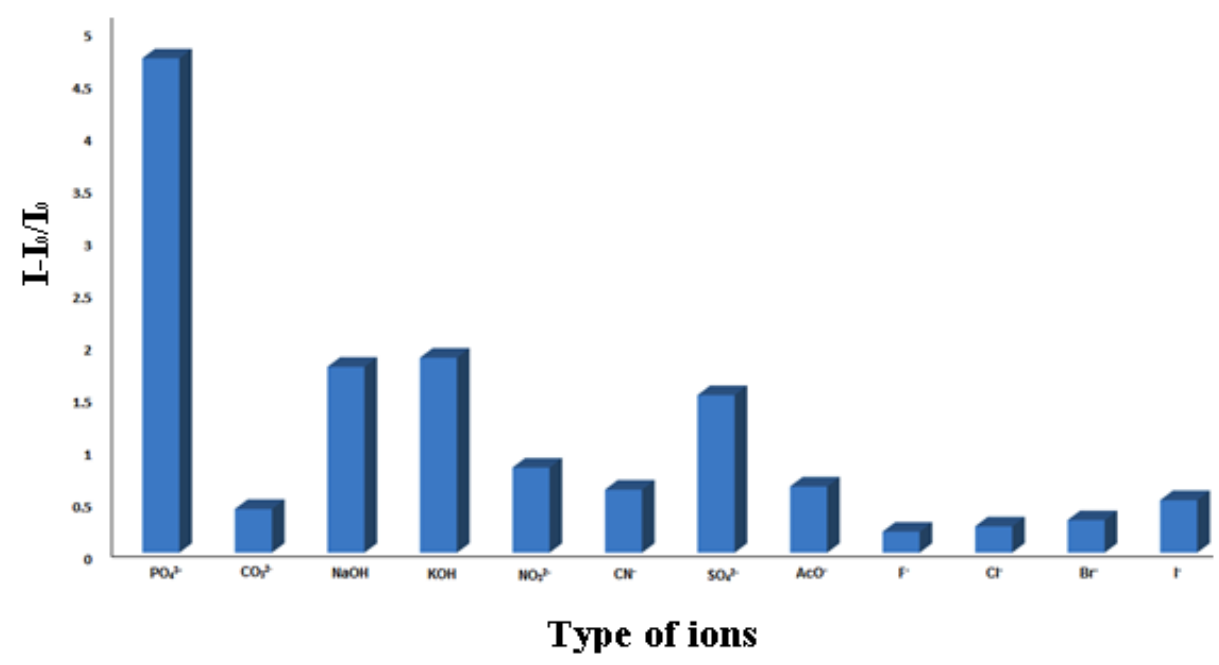

Figure 7. Selectivity of BNCQD towards $\mathrm{PO}_{4}{ }^{3-}$ ion

\section{Conclusion}

In conclusion, we wish to introduce a specific, highly selective and rapid assay for the detection of $\mathrm{PO}_{4}{ }^{3-}$ anion. Fluorescent B-doped carbon quantum dots is synthesized via a simple and one-pot MWassisted method and is used as environmentally friendly and biocompatible sensor of $\mathrm{PO}_{4}{ }^{3-}$ for the first time. The sensitivity is based on the coordination of $\mathrm{PO}_{4}{ }^{3-}$ anion via its oxygen-donors to $\mathrm{B}$ atoms in the BNCQD structure. Fluorescence intensity of BNCQD is increased by the coordination of $\mathrm{PO}_{4}{ }^{3-}$. The fluorescence increasing efficiency is linearly correlated with the $\mathrm{PO}_{4}{ }^{3-}$ concentration.

\section{Acknowledgements}

Financial support of this work by the research affairs of Azarbaijan Shahid Madani University is gratefully appreciated.

\section{Supporting Information}

Supporting information accompanies this paper on http://www.acgpubs.org/journal/organic$\underline{\text { communications }}$

\section{ORCID}

Azadeh Ostad Chinigar: 0000-0002-6963-2976

Ashkan Shomali: 0000-0003-3085-4085

Hassan Valizadeh: 0000-0002-8316-3221 


\section{References}

[1] Lin, S. H.; Wu, C. L. Removal of nitrogenous compounds from aqueous solution by ozonation and ion exchange. Water Res. 1996, 30, 1851-1857.

[2] Levine, S.; Schindler, D. Phosphorus, nitrogen, and carbon dynamics of Experimental Lake 303 during recovery from eutrophication. Can. J. Fish. Aquat. Sci. 1989, 46, 2-10.

[3] De-Bashan, L. E.; Bashan, Y. Recent advances in removing phosphorus from wastewater and its future use as fertilizer. Water Res. 2004, 38, 4222-4246.

[4] Almeelb,T. I; Bezbaruah, A. Aqueous phosphate removal using nanoscale zero-valent iron," in Nanotechnology for Sustainable Development. Springer, Cham, 2012, 197-210

[5] Kumar, M.; Badruzzaman, M.; Adham, S. Beneficial phosphate recovery from reverse osmosis (RO) concentrate of an integrated membrane system using polymeric ligand exchanger (PLE). Water Res. 2007, 41, 2211-2219.

[6] Oehmen, A.; Lemos, P. C.; Carvalho, G.; Yuan, Z.; Keller, J. L.; Blackall, L.; Reis, M. A. Advances in enhanced biological phosphorus removal: from micro to macro scale. Water Res. 2007, 41, 2271-2300.

[7] Zhang, G.; Liu, H.; Liu, R.; Qu, J. Removal of phosphate from water by a Fe-Mn binary oxide adsorbent. J. Colloid Interfa. Sci. 2009, 335, 168-174.

[8] Gam M. X.; Liu, C. F.; Wu, Z. L.; Zeng, Q. L.; Yang, X. X.; Wu, W. B.; Li, Y. F.; Huang, C. Z. A surfactantassisted redox hydrothermal route to prepare highly photoluminescent carbon quantum dots with aggregation-induced emission enhancement properties. Chem. Commun. 2013, 49, 8015-8017.

[9] Liu, C.; Zhang, P.; Zhai, X.; Tian, F.; Li, W.; Yang, J.; Liu, Y.; Wang, H.; Wang, W.; Liu, W. Nanocarrier for gene delivery and bioimaging based on carbon dots with PEI-passivation enhanced fluorescence. Biomaterials 2012, 33, 3604-3613.

[10] Jahan, S.; Mansoor, F.; Naz, S.; Lei, J.; Kanwal, S. Oxidative synthesis of highly fluorescent boron/nitrogen co-doped carbon nanodots enabling detection of photosensitizer and carcinogenic dye. Anal. Chem. 2013, 85, 10232-10239.

[11] Das, G. S.; Tripathi, K. M.; Kumar, G.; Paul, S.; Mehara, S.; Bhowmik, S.; Pakhira, B.; Sarkar, S.; Roy, M.; Kim, T. Y. Nitrogen-doped fluorescent graphene nanosheets as visible-light-driven photocatalysts for dye degradation and selective sensing of ascorbic acid. New J. Chem. 2019, 43, 14575-14583.

[12] Lu, F.; Zhou,Y.H.; Wu, L.H.; Qian, J.; Cao, S.; Deng, Y.F.; Chen, Y. Highly fluorescent Nitrogen-doped graphene quantum dots' synthesis and their applications as Fe (III) ions sensor. Int. J. Opt. 2019, |Article ID 8724320, (9 pages).

[13] Bai, J. M.; Zhang, L.; Liang, R. P.; Qiu, J. D. Graphene quantum dots combined with europium ions as photoluminescent probes for phosphate sensing. Chem. Eur. J. 2013, 19, 3822-3826.

[14] Qin, J; Li, D; Miao, Y; Yan, G. Detection of phosphate based on phosphorescence of Mn doped ZnS quantum dots combined with cerium (iii). R.S.C. Adv. 2017, 74, 46657-46664.

[15] Yan, D; He, Y; Ge, Y; Song, G. Fluorescent detection of phosphate in aqueous solution based on near infrared emission Ag2S QDs/metal-organic shell Composite. J. Fluoresc. 2017, 1, 227-233.

[16] Dai, C; Yang, CX; Yan, X.P. Ratiometric fluorescent detection of phosphate in aqueous solution based on near infrared fluorescent silver nanoclusters/metal-organic shell composite. Anal. Chem. 2015, 87, 1145511459.

[17] Shomali, A.; Valizadeh, H.; Banan, A. Efficient synthesis of xanthene derivatives using carboxyl functionalized graphene quantum dots as an acidic nano-catalyst under microwave irradiation. RSC. Adv. 2015, 5, 88202-88208.

[18] Valizadeh, H.; Shomali, A.; Nourshargh, S.; Mohammad-Rezaei, R. Carboxyl and nitrite functionalized graphene quantum dots as a highly active reagent and catalyst for rapid diazotization reaction and synthesis of azo-dyes under solvent-free conditions. Dyes Pigments 2015, 113, 522-528.

[19] Shomali, A.; Valizadeh, H. Efficient Synthesis of Ît-Oximinoketones using carboxyl and nitrite functionalized graphene quantum dots: Dual role of nanostructure as a catalyst and reagent. J. Adv. Chem. 2016, 12, 4089-4096.

[20] Baker, S. N.; Baker, G. A. Lumineszierende kohlenstoff-nanopunkte: Nanolichtquellen mit zukunft. Angew. Chim. 2010, 122, 6876-6896.

[21] Shen J., Y. Zhu, X. Yang, J. Zong, C. Li, One-pot hydrothermal synthesis of graphene quantum dots surfacepassivated by polyethylene glycol and their photoelectric conversion under near-infrared light. Chem. Commun. 2012, 36, 97-101.

[22] Li, H.; Kang, Z.; Liu, Y.; Lee, S.T. Carbon nanodots: synthesis, properties and applications. J. Mat. Chem. 2012, 22, 24230-24253. 
[23] Sun, Y.-P.; Zhou, B.; Lin, Y.; Wang, W.; Fernando, K. S.; Pathak, P.; Meziani, M. J.; Harruff, B. A.; Wang, $\mathrm{X}$; Wang, vc BC9H. Quantum-sized carbon dots for bright and colorful photoluminescence. J. Am. Chem. Soc. 2006, 128, 7756-7757.

[24] Jaiswal, A.; Ghosh, S. S.; Chattopadhyay, A. One step synthesis of C-dots by microwave mediated caramelization of poly (ethylene glycol). Chem. Commun. 2012, 48, 407-409.

[25] Yang, Y.; Cui, J.; Zheng, M.; Hu, C.; Tan, S.; Xiao, Y.; Yang, Q.; Liu, Y.; One-step synthesis of aminofunctionalized fluorescent carbon nanoparticles by hydrothermal carbonization of chitosan. Chem. Commun. 2012, 48, 380-382.

[26] Qian, Z.S.; Ma, J.J.; Shan, X. Y.; Shao, L. X.; Zhou, L.; Chen, J. R.; Feng, H. Surface functionalization of graphene quantum dots with small organic molecules from photoluminescence modulation to bioimaging applications: an experimental and theoretical investigation. R.S.C. Adv. 2013, 3, 14571-14579.

[27] Panchakarla, L. S.; Subrahmanyam, K. S.; Saha, S. K.; Govindaraj, A.; Krishnamurthy, H. R.; Waghmare, U. V.; Rao, C. N. R. Synthesis, structure, and properties of boron-and nitrogen-doped grapheme. Adv. Mat. 2009, 21, 4726-4730.

[28] Subrahmanyam, K. S.; Panchakarla, L. S.; Govindaraj, A.; Rao, C. N. R. Simple method of preparing graphene flakes by an arc-discharge method. J. Phys. Chem. C 2009, 113, 4257-4259.

[29] Sheng, Z.H.; Gao, H.L.; Bao, W.J.; Wang, F.B.; Xia, X.H. Synthesis of boron doped graphene for oxygen reduction reaction in fuel cells. J. Mat. Chem. 2012, 22, 390-395.

[30] Wang, H.; Maiyalagan, T.; Wang, X. Review on recent progress in nitrogen-doped graphene: synthesis, characterization, and its potential applications. ACS Catal. 2012, 2, 781-794.

[31] Marconcini, P.; Cresti, A.; Triozon, F.; Fiori, G.; Biel, B.; Niquet, Y.M.; Macucci, M.; Roche, S.; Atomistic boron-doped graphene field-effect transistors: a route toward unipolar characteristics. ACS Nano. 2012, 6 , $7942-7947$.

[32] Yang, Y.; Cui, J.; Zheng, M.g.; Hu, C.; Tan, S.; Xiao, Y.; Yang, Q.; Liu, Y. One-step synthesis of aminofunctionalized fluorescent carbon nanoparticles by hydrothermal carbonization of chitosan. Chem. Commun. 2012, 48, 380-382.

[33] Zhai, X. Y.; Zhang, P.; Liu, C. J.; Bai, T.; Li, W. C.; Dai, L.; Liu, W. G. Highly luminescent carbon nanodots by microwave-assisted pyrolysis. Chem. Commun. 2012, 48, 7955-7957.

[34] Xu, Y.; Wu, M.; Liu, Y.; Feng, X. Z.; Yin, X. B.; He, X. W.; Zhang, Y. K. Nitrogen-doped carbon dots: A facile and general preparation method, photoluminescence investigation, and imaging applications. Chem. Eur. J. 2013, 19, 2276-2283.

[35] Zheng, A. X.; Cong, Z. X.; Wang, J. R.; Li, J.; Yang, H. H.; Chen, G. N. Highly-efficient peroxidase-like catalytic activity of graphene dots for biosensing. Biosens. Bioelectron. 2013, 49, 519-524.

[36] Ryther, H.; Dunstan, W. M. Nitrogen, phosphorus, and eutrophication in the coastal marine environment. Science 1971, 171, $1008-1013$.

[37] Gupta, V.; Chaudhary, N.; Srivastava,; Sharma, R. G. D.; Bhardwaj, R.; Chand, S. Luminscent graphene quantum dots for organic photovoltaic devices. J. Am. Chem. Soc. 2011, 133, 9960

[38] Wu, J. S.; Pisula, W.; Mullen, K.; Graphenes as potential material for electronics. Chem. Rev. 2007, 107, 718-747.

[39] Qu, S.; Wang, X.; Lu, Q.; Liu, X.; Wang, L. A. A biocompatible fluorescent ink based on water-soluble luminescent carbon nanodots. Angew Chem. Int. Ed. 2012, 51, 12215-12218.

[40] Pan, D.; Zhang, J.; Li, Z.; Wu, C.; Yan, X.; Wu, M. Observation of pH-, solvent-, spin-, and excitationdependent blue photoluminescence from carbon nanoparticles. Chem. Commun. 2010, 46, 3681-3683.

[41] Brown, R. M.; McClell, N. I.; Deininger, R. A.; Tozer, R. G. A Water quality index: Do we dare? Water Sew. Work. 1970, 117, 339-343.

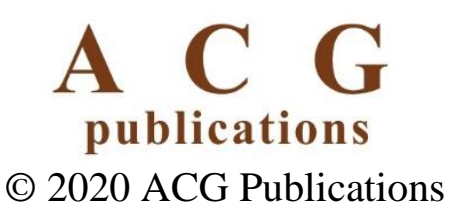

